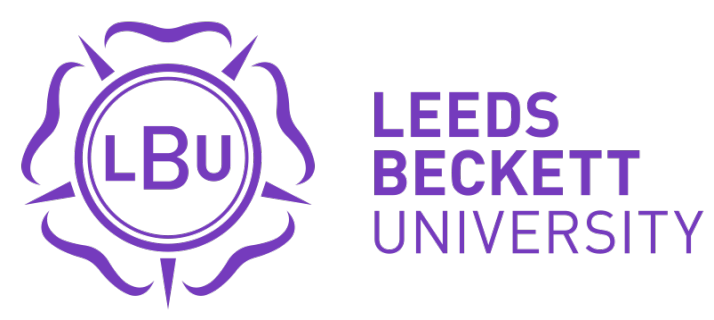

Citation:

Maher, AJ and Fitzgerald, H (2020) Initial teacher education and continuing professional development : the perspectives of special school physical education teachers. Curriculum Studies in Health and Physical Education, 11 (1). pp. 18-33. ISSN 2574-2981 DOI: https://doi.org/10.1080/25742981.2019.1696687

Link to Leeds Beckett Repository record:

https://eprints.leedsbeckett.ac.uk/id/eprint/6526/

Document Version:

Article (Accepted Version)

Creative Commons: Attribution-Noncommercial-No Derivative Works 4.0

This is an Accepted Manuscript of an article published by Taylor \& Francis in Curriculum Studies in Health and Physical Education on 01 Dec 2019, available online: http://www.tandfonline.com/10.1080/25742981.2019.1696687

The aim of the Leeds Beckett Repository is to provide open access to our research, as required by funder policies and permitted by publishers and copyright law.

The Leeds Beckett repository holds a wide range of publications, each of which has been checked for copyright and the relevant embargo period has been applied by the Research Services team.

We operate on a standard take-down policy. If you are the author or publisher of an output and you would like it removed from the repository, please contact us and we will investigate on a case-by-case basis.

Each thesis in the repository has been cleared where necessary by the author for third party copyright. If you would like a thesis to be removed from the repository or believe there is an issue with copyright, please contact us on openaccess@leedsbeckett.ac.uk and we will investigate on a case-by-case basis. 


\title{
Initial teacher education and continuing professional development: the perspectives of special school physical education teachers
}

\begin{abstract}
Physical education (PE) research focusing on initial teacher education (ITE) and continuing professional development (CPD) has been preoccupied with practitioners in mainstream (regular) schools. This article used situated learning theory to explore special school PE teachers' perspectives of their ITE and CPD in England. A number of key themes were constructed from six interviews with special school teachers, including, 'Special educational needs and disabilities is marginalised during initial teacher education', 'Special school-based placement may help to prepare trainee teacher', 'The professional development opportunities available to special school PE teachers are limited' and 'PE-specific CPD should be tailored to the needs of staff and pupils in schools'. Regardless of route into the profession, all teachers recalled a lack of focus on Special Educational Needs and Disabilities (SEND) and inclusion in the context of PE during their ITE. This trend was also evident through subsequent CPD offered, although there were accounts of informal opportunities. In concluding we argue that further consideration must be given to the nature of inclusive PE training offered within ITE. There is also a need to reconsider how CPD can best support career-long professional development that nurtures inclusive PE practitioners.
\end{abstract}

\section{Key words}

Special school physical education, inclusive physical education, initial teacher education and continuing professional development

\section{Introduction}

In 2015 the United Nations developed Sustainable Development Goals to reduce extreme poverty and exclusion by 2030 , one of which was to ensure that education systems around the world offer inclusive and equitable experiences for all (UNESCO, 2017). Here, attention is paid to the estimated one billion individuals with one or more physical, sensory, intellectual or mental health impairments (WHO, 2016). The success of such commitments is tied to the contextually-dependent legislation and strategies developed in specific countries because 
developments differ between international contexts. Nonetheless, it is encouraging that many countries have developed policies in an attempt to ensure that children with disabilities have meaningful educational experiences; see, for example, Australia (Commonwealth of Australia, 2006), New Zealand (Ministry of Social Development, 2016) and Britain (DfE/DoH, 2015). Within these countries, and indeed others, it is mainstream (regular) schooling that has been advocated as the preferred means of educating children with disabilities. The most recent special educational needs and disability (SEND) code of practice (DfE/DoH, 2015) in Britain, for instance, provided statutory guidance that schools must follow to ensure that children with SEND are included in mainstream schools. Here, the Office for Standards in Education, Children's Services and Skills (Ofsted) act as a regulatory mechanism that assess the quality and appropriateness of the provision provided to children with SEND, as well as the academic attainment of those children (Ofsted, 2018). In a parallel development, similar to Australia (see AITSL, 2010), increasing pressure has been placed on mainstream school teachers to ensure their pedagogies are inclusive. For instance, the Teachers' Standards (DfE, 2011), which are described as 'the minimum level of practice expected of trainees and teachers from the point of being awarded qualified teacher status' (3), explicitly relate to the teaching and educational inclusion of children with SEND.

Despite there being a taken-for-granted assumption that mainstream schools are the most appropriate means of educating most children with SEND, there is an extensive body of evidence suggesting that pupils with SEND perform significantly worse than those without SEND in reading, writing and mathematics throughout their entire schooling (ages 5-16) (DfE 2018). When light is cast on physical education (PE), research suggests that pupils with SEND participate less frequently and in a narrower range of physical activities than their age-peers, both during (e.g. Vickerman \& Maher, 2018) and after school (e.g. Haycock \& Smith, 2011). 
This is despite the potential positive influence of 'inclusive PE' on attitudes towards disability of children without disabilities (Ruscitti et al., 2017). One reported reason for these disparate opportunities and experiences is because in-service PE teachers lack the knowledge, skills and experience to teach pupils with SEND (Vickerman and Coates, 2009). Consequently, some academics (e.g. Vickerman \& Maher, 2018) have called for initial teacher education (ITE) programmes to better prepare prospective PE teachers for teaching pupils with SEND.

There is notably little consensus about how best to prepare PE teachers for their role as inclusive educators. Interestingly, academics, teacher educators and teachers of all subjects are struggling to agree upon, as Florian and Linklater (2010, p. 369) remind us, 'what constitutes necessary knowledge and skills.... what classroom teachers need to know and how they might be prepared to work in inclusive classrooms'. In this respect, Dart (2006) offers a useful guide for ITE and professional development, suggesting that they should (1) allow pre- and in-service teachers to develop positive attitudes towards children with SEND; (2) give teachers the skills to enable them to support children with SEND; and (3) develop appropriate pedagogical content knowledge through teaching practice. The PE-specific research in the field has largely developed along these lines. Haegele et al. (2018), for instance, examined the impact of a twoday professional development workshop on the attitudes of mainstream school teachers towards children with SEND. The workshop was found to impact positively but did not allow the participants to work directly with children with SEND, which should be, according to Coates (2012), an integral aspect of ITE. Indeed, Ellins and Porter (2005) found that teachers with no SEND training had the least positive attitude towards inclusion and those with most training were more positive. The proposed importance of gaining hands-on experience working with children with SEND has spawned research evaluating the impact of such experiences on the professional development of prospective PE teachers. Maher et al. (2019), for example, 
evaluated the influence of a placement in a special school on self-perceptions of competence and confidence in relation to teaching pupils with SEND.

A key limitation of current research relating to teacher education for inclusion in PE is that it focuses, almost entirely, on the professional socialisation of mainstream school teachers. That said, there are some who are endeavouring to better understand how key socialising agents such as parents (O’Leary et al., 2014) and former teachers (O’Leary, 2015) during primary socialisation, and colleagues and pupils (O’Leary et al., 2014, 2015) as part of organisational socialisation, influence the pedagogies of special school PE teachers. Recently, colleagues in the United States (US) have explored the experiences leading individuals to enrol in a graduatelevel adapted physical education teacher education programme (Richards and Wilson, 2019). In this respect, it is noteworthy that in Britain there are no specific graduate or postgraduate PE teacher education programmes aimed at developing specialist teachers of special school PE, which adds to the need for research exploring the ITE and CPD of those currently in that role. The lack of research in this field is, perhaps, indicative of the assumption that posits mainstream schools as the preferred means of provision for pupils with SEND. We believe such a narrow focus is problematic given more recent calls to radically rethink and restructure the education system. Baroness Warnock, whose report (DES, 1978) was instrumental to the mainstreaming of education in Britain, is one of a number of politicians and academics who have claimed that special schools may be a more appropriate context for some of the children with SEND currently educated in mainstream schools (Warnock, 2010). Here, we agree with Baroness Warnock when she suggests that children should be educated 'wherever they can learn best' (Warnock, 2010, p. 14) whether that be mainstream, special, or a combined iteration. Nonetheless, whilst the PE-specific comparative data is limited, it has long been said that pupils with SEND participate more frequently in PE in special schools than those with SEND in a 
mainstream context (Sport England, 2001). The significance of this point becomes more apparent when we remember that the learning needs of those in special schools are generally more profound, diverse and complex than pupils with SEND in mainstream schools (Maher, 2018).

Whilst we recognise there is a buoyant debate regarding mainstream versus special schooling, we do not wish to explicitly add to these discussions here. Instead, our focus is on gaining a sense of how well-prepared special school teachers are to teach PE. This is crucial given that some of those who deliver PE in special schools may not be trained nor qualified PE teachers. Therefore, equal light must be cast on the extent to which the professional development opportunities, something which is absent from the literature, of special school PE teachers prepares them for their role as inclusive educators. The research reported in this article aims to explore the ITE and CPD of special school PE teachers in order to better understand (1) the nature of their ITE and CPD experiences; (2) the extent to which these experiences have prepared them to teach PE; and (3) the ways in which ITE and CPD can be enhanced to more adequately prepare special school PE teachers. Whilst the focus of our research centralises those working in a special school, it is important to note, as Hegarty (2007) did, that some inclusive practices in special schools originated in mainstream schools, and effective practices in special schools can be found in mainstream education. Therefore, teacher educators, schools and teachers (both mainstream and special) can use our findings to reflect on their own policies and practices in order to consider ways of improving the education of all children, not just those with SEND. In this respect, we agree with Wedell (2005, p. 7), who believes that 'effective teaching for those with special needs has direct relevance to effective teaching in general'. The next section explores, albeit briefly, our conceptualisation of situated learning theory as this was used to help us make sense of the learning and experiences of special school PE teachers. 


\section{Situated learning theory}

Situated learning theory was developed to challenge the dominance of theoretical paradigms that placed the mind and mental processes at the centre of our understandings of learning (see Bruner, 2006). In this respect, Lave and Wenger (1991) postulate that learning is a collective social activity, the outcome of which is the construction of contextualised knowledge. One of Lave and Wenger's (1991) most noteworthy scholarly contributions was to give primacy to the 'practice' aspect of the theory-practice dichotomy by considering thinking and learning as something that is experienced by teachers as they become a member of a community of practice in special schools. For us, it is the social practices and interactions that happen during ITE and in the special schools that are the subject of our inquiry because it is these that will shape teachers' learning about teaching PE to pupils with SEND. Here, our research aligns with others (e.g. Korthagen, 2010) who have used situated learning theory to explore teacher professional learning.

\section{Research context and participant recruitment}

This article reports on one dimension of a larger research project that explored the culture of special school PE. Here, we focus on the semi-structured interviews that were conducted with the six teachers about their PE ITE and CPD experiences. We already had well-established relationships with special schools in Yorkshire, England, and we drew on these networks to recruit participants. All schools were governed by the same local authority and catered for pupils with diverse learning needs, including, but not exclusively, those with physical, sensory and learning disabilities, as well as those experiencing social, emotional and mental health (SEMH) difficulties. None of the schools 'specialised' in specific learning needs, and all 
supported children and young people aged 5 - 18. In taking a convenience sampling approach we initially emailed the head teacher of each special school $(n=6)$ and offered an overview of the research and invited their involvement. Once confirmation was received, the lead author visited the school to further discuss the research, answer questions and arrange interviews. We wanted to recruit participants with a range of experiences in relation primary and secondary ITE, and subject area, in order to provide a more complex and nuanced discussion of ITE experiences. Table 1 provides an overview of those interviewed.

Table 1 - Research participants

\begin{tabular}{|l|l|l|}
\hline \multicolumn{1}{|c|}{ Name } & $\begin{array}{c}\text { Type of ITE } \\
\text { (all mainstream) }\end{array}$ & \multicolumn{1}{|c|}{ ITE Subject } \\
\hline Adam & Secondary & PE \\
\hline Gareth & Secondary & PE \\
\hline Sophie & Secondary & Maths \\
\hline Emma & Primary & Generalist \\
\hline Jessica & Primary & Generalist \\
\hline Ruth & Primary & $\begin{array}{l}\text { Generalist } \\
\text { (specialising in PE) }\end{array}$ \\
\hline
\end{tabular}

\section{Data gathering}

Interview questions were open, which enabled participants to expand on issues where necessary. Designing the interview schedule in this way also offered opportunities to probe and clarify during the interview process. These kind of follow up questions aided the generation of what Sparkes and Smith (2014) describe as thick descriptions; that is, accounts of situated learning experiences salient to the teacher's social subjective realities relating to their ITE and CPD experiences. Interviews were conducted in the school where the participants worked and 
arrangements were made for these to take place in a private room. Before the beginning of each interview an information letter and consent form was given to each participant. This included details about the purpose of the research and the process of data collection. Following BERA's (2018) research ethics guidelines, the information letter also outlined how anonymity and confidentiality would be maintained and the participants' right to withdraw. During this time the research participants were invited to ask questions about the research and clarify any information given in the letter. We were keen to reiterate to each person that the interview would be treated in the strictest confidence. This was particularly important given that teachers knew that their line-managers would be interviewed. With the permission of the research participants all interviews were audio recorded. These were then transcribed verbatim. Interviews lasted approximately 60 minutes each.

\section{Data analysis}

Braun and Clarke's (2013) phases of reflexive thematic analysis were used. First, the combined processes of conducting the interviews, listening to the audio files and reading the interview transcripts meant that the researchers became familiar with these data and began to make notes about connections within and across transcripts. Next, [Author] manually generated initial codes. This involved the identification of 'chunks' of text relating to units of meaning-patterns (Braun et al., 2018). Here, attempt was made to move beyond the coding of superficial, semantic meaning, towards the construction of latent codes (Braun et al., 2018). The next phase involved the building of candidate themes. This comprised sorting the codes into clusters of 'meaning that tell a story about a particular aspect of the dataset' (Braun et al., 2018: 12). We were also guided by Sparkes and Smith (2014) who believe this process should bring to the fore the common threads and meaningful essence that runs through these data. Once candidate 
themes and interview extracts had been established, they were sent to [Author] for consideration. Given that we, the researchers, have differing lived experiences, academic knowledge and observe the social world through different theoretical lenses, the purpose here was to act as a critical friend, enabling [Author] to reflect on the decisions made during coding and the grouping of codes and interview text. Indeed, [Author] role was to encourage reflexivity by checking and challenging [Author] construction of candidate themes (Smith \& McGannon, 2017). This was particularly useful for reducing theme overlap, which is important for 'clarifying the essence and scope of each theme' (Braun et al., 2019:13). Subsequently, a number of key themes were established including 'Special educational needs and disabilities is marginalised during initial teacher education', 'Special school-based placement may help to prepare trainee teacher', 'The professional development opportunities available to special school PE teachers are limited' and 'PE-specific CPD should be tailored to the needs of staff and pupils in schools'. Each of these themes are now used to tell a story about the ITE and CPD of special school PE teachers.

\section{Special educational needs and disabilities is marginalised during initial teacher} education

As Table 1 outlines, all of the teachers interviewed trained as mainstream (regular) schoolteachers. Two of the teachers, Adam and Gareth, specialised in secondary PE. Interestingly, Ruth qualified as a generalist primary school (ages 5-11) teacher and elected to specialise in PE during her ITE. Initially, it would seem three of the six teachers were at least likely to have developed relevant content knowledge relating to PE (e.g. rules, tactics, activity skills). Ruth, though, was critical of the quality and usefulness of the PE content knowledge she received during her primary ITE: 
we did a lesson [in a school during placement]. It wasn't like they taught you how to teach a lesson, if that makes sense? We just went and actually participated... Sort of like turn up to play a game of netball. I thought, well, I can do that. You're meant to be teaching me how to teach it... And the specialism we just basically picked an element, so me and my group picked dance, and we had to go into school ... we had to plan it and deliver it, but ... it was us doing it. We had very little support.

From this and other accounts offered by Ruth it appears that content knowledge relating to PE was developed to some extent. However, Ruth's ITE did not enable her to develop the pedagogical skills required to plan and deliver PE lessons, which is said to be an integral aspect of the professional learning of aspiring and in-service PE teachers (Dely et al., 2015). Or as she put it, 'teaching me how to teach it [PE]'. Whilst there continues to be a buoyant debate about the balance of content and pedagogical knowledge offered during PE ITE (Capel et al., 2011), we would suggest these discussions become more sharply focused when teachers are also expected to plan and deliver PE lessons to pupils whose needs are more broad, diverse and complex than those typically found in mainstream schools (Maher, 2018). Here the expectations widen in PE as the trainees need to develop insights about SEND pupils and inclusive pedagogies, all within a curriculum area that is very different to other subjects they are expected to teach.

It was apparent from the interviews that all of the teachers had very little SEND or inclusion training during their ITE, regardless of their route into the profession. Those who had received SEND training were critical of the lack of application and relevance to PE. Adam, a trained secondary school PE teacher, explained:

The way I went into PE, it was the graduate teacher programme. My training was very much reliant on my school setting. The training that I had was very generic teacher training, there were no specialist sessions... you got together as a cohort of training teachers of 15, 20 of you ... but from every subject, and you had core sessions on behaviour management, or SEN as a general theme, or differentiation... so that was ... yeah, just kind of teaching ... general. 
It is not uncommon to hear of generic SEND and inclusion issues being covered during ITE (see Vickerman \& Coates, 2009; Coates, 2012). This approach is particularly valuable for developing foundational knowledge about SEND and inclusion. However, we caution relying wholeheartedly on this strategy as it may not be an effective approach for those working in PE, given that the concept of SEND is contextual and situational (Maher, 2018). For example, a pupil who uses a wheelchair may not require additional provision in an English lesson, may not during a swimming lesson, but is likely to if the lesson is football played on the school field. The consequences of this are that those who teach corporeal practices in different and, at times, changing spaces such as PE, have to overcome challenges to learning that classroombased teacher may not, and vice-versa. In this respect, Vickerman and Coates (2009) found that much of the inclusion training that pre-service PE teachers did receive was classroom-based, leaving them questioning its applicability and relevance to PE. From a professional learning perspective, Armour and Yelling (2007) are critical of such decontextualised experiences, arguing that learning should be tied to the specific settings in which pre-service teachers will find themselves once they qualify. The consequences of a lack of contextualised learning is conveyed by Adam when he reflected on his practice:

It's [inclusion training] massively important, it's been a struggle for me at times, as someone who's PE-trained, it's not always easy, I sometimes look at the group I've got, and I'll think, what am I going to do with this group, and it will take a long time to plan a session, and a lot of research.

Significantly, Adam also acknowledges the difficulties he experiences in special school PE in spite of his specialist PE teacher training. This raises another important issue about ITE: the kind of training relating to PE content knowledge that is typically offered through ITE, often in a very decontextualised manner, may not enable teachers to effectively deliver to the range 
of pupils attending special school settings. We make this point because PE training and practices are anchored in tradition and this reproduces normative ideas about ability and performance (Backman \& Larsson, 2016; Fitzgerald, 2005). As a consequence, those that have received PE ITE training may not be offered this in a way that acknowledges the different kind of pupils educated in special schools. We would therefore question if Sophie, Emma and Jessica were constrained in anyway because they were not PE trained during ITE. Here, it appears that situated learning (Lave and Wenger, 1991) in special schools would be a key aspect of the professional learning of these teachers, rather than decontexualised PE content knowledge.

\section{Special school-based placement may help to prepare trainee teacher}

Another key point that came through interview discussions related to the importance of preparing pre-service teachers for the contextual realities of working in special schools. Emma, for instance, stated:

I'd say to anybody [coming to work in a special school] don't be embarrassed. There's days where I'm pretending to be a slug or a snail... if you want to work with special needs kids, especially in PE, then you need a sense of humour, because there's things you're going to do where you think, oh, what am I actually doing today? You're running around as a pterodactyl, or you're pretending you've got goofy teeth, because they think it's funny and they'll run after you, it's things like that, just don't be embarrassed.

In order to be exposed to this kind of experience, special school-based placements have been identified by some (see Arthur-Kelly et al., 2013; Golder et al., 2009; Maher et al., 2019) as a meaningful activity for gaining insights about working with children with SEND in the contexts and learning situations in which prospective teachers will find themselves. Interestingly, some of the teachers in our research also highlighted the importance of a special school-based placement being a part of ITE. Adam suggested: 
When you speak to trainees... nobody really knows what happens in special ed. We had someone in recently, who was on a teacher training course, and she was on placement at another school, and she said could she do a week on placement here to observe, and at the end of the week, she had no idea what was on offer ... well, she admitted, sorry, she'd had no idea what was on offer until she came, and she absolutely loved her placement, and I think it should be a bigger part of teacher training in general.

According to Arthur-Kelly et al (2013, p. 220) 'placements provide ideal opportunities for preservice teachers to trial, reflect on and refine the beliefs, attitudes, knowledge and skills discussed and developed in university courses', something that is essential for the development of positive attitudes towards teaching of children with SEND. For Golder et al. (2009), placements serve to increase pre-service teacher knowledge and understanding of SEND provision and awareness of a range of teaching and learning strategies underpinning inclusive practice. In relation to PE, Maher et al. (2019), who drew on situated learning theory, found special school placements facilitated increases in confidence and competence of prospective PE teachers. It is noteworthy that these studies focus on the short-term impact of placement in a special school. We do not know if these reported increases in attitude, knowledge, skills and confidence are superficial and ephemeral, or deeply embedded and long-lasting. Longitudinal and/or revisit studies are perhaps required to answer this question, particularly given the 'wash out' that can happen during a teacher's occupational socialisation (Zeichner and Tabachnick, 1981).

Interestingly, some of the prospective teachers from our university had been on placement at Gareth's school, something that he complimented: 'I think you've made headway by opening the doors by allowing students to come in and work with us'. Gareth continued:

When you're at university you do what is necessary, get your qualification but I think it's up to ... I was going to say us guys, up to you guys [teacher educators] to say look, this is what being realistic is all about. And I think you've got to point them in the direction that this is going to hit you hard and this is what you're going to have to do. 
Here, Gareth is alluding to the challenges associated with working in a special school, many of which are unique to that educational context. This point becomes even more significant given that the vast majority of school-based placements that pre-service PE teachers experience will be in mainstream schools. Therefore, those who aspire to teach PE in special schools will not be exposed to the settings nor situated experiences (Lave and Wenger, 1991) necessary for contextualised learning until they gain employment. Maher et al. (2019) are among a growing number of academics and teacher educators who have appealed for special school placements to feature more prominently in ITE programmes to ensure that prospective teachers experience relevant contextual learning. Accordingly, they have developed a role transitional model for trainee teachers, which involves observing lessons, supporting the delivery of lessons, and then delivering lessons with the support of an experienced special school PE teacher acting as mentor (Maher et al., 2019). This kind of approach may go some way to, as Gareth suggests, prepare them for how hard working in a special school will 'hit' trainee teachers.

\section{The professional development opportunities available to special school PE teachers are limited}

Once discussions relating to ITE drew to a close, the professional development opportunities of special school PE teachers became the focal point. When it came to what CPD opportunities were offered to staff, views and experiences often varied. Sophie and Adam, for example, had received some PE-specific CPD and were positive about having these opportunities:

No, I haven't done much [PE CPD]. I think the first thing I've done ... well, I was rebound [therapy] trained, and then it's just been this MATP [motor activity training programme] thing, quite recently (Sophie). 
We've got two staff that are just in the process of completing their rebound trainer's course. So then they'll be able to deliver in-school rebound training to everybody else, so that's really good. We are going to be having an inset on the swimming curriculum so that all staff are in a position to deliver that to the best of their ability. Other than that, we're fairly limited to what's delivered (Adam).

It is interesting to note that these CPD opportunities, like much PE ITE, focused on developing relevant content knowledge in relation to PE (Capel et al., 2011). Indeed, the opportunities provided were usually indicative of the needs of the children attending the school in question. In this respect, this CPD offered relevant and useful content and knowledge that the special school PE teachers could utilise. For example, it was perhaps no surprise that both Sophie and Adam mentioned rebound therapy training given that many of the children attending their schools experienced complex learning difficulties, as well as social, emotional and mental health (SEMH) issues. This is a good example of school leaders facilitating professional learning that is tailored to the context and situations germane to teachers (Armour and Yelling, 2007).

In most instances, there was a lack of PE-specific CPD opportunities offered to participants. However, there were a number of ways in which teachers claimed to be developing professionally in more informal capacities. It is widely acknowledged that informal and collaborative learning with colleagues can be an effective means of supporting professional development (Parker \& Patton, 2017). For instance, Ruth discussed what she had learned 'on the job' from a former colleague at her school and colleagues at other special schools:

The old Deputy Head, who retired from here, he was PE, so I learnt a lot more from working with him than I did at uni [training] ... and even just sharing ideas with different special schools, and seeing how their sensory PE works... we are quite good at working with other schools... we have inter-school events with the other special schools. 
The significance of knowing how teachers interact and collaborate in order to learn and share manifests in research that focuses on teacher networks, communities of practice/learning, as well as teacher-mentor/coach relations (Chambers, 2015). Depending on the early and professional socialisation of newly qualified teachers (NQTs), their beliefs and values, and the extent to which the culture of schools facilitate learning and professional development of new staff, an appropriately skilled and experienced teacher-mentor can help NTQs to assimilate into their school and profession (Avalos, 2011).

What is less well-researched is the ways in which the impact of the wider professional network of teachers, such as those working at other special schools, contributes to their professional development. Often, focus is cast on teacher co-learning within schools (e.g. Mawhinney, 2010) but less so across schools. Thus, future research may be required to gain a better understanding of how educational authorities and schools can develop and facilitate a community of practice (Lave and Wenger, 1991) across (special) schools. This may be particularly beneficial to special school PE teachers, many of whom are the only deliverer of PE in their school and some of whom appear insufficiently trained and supported to fulfil this role.

Gareth mentioned the importance of lesson observations as a mechanism for co-learning and professional development. Interestingly, he highlighted the importance of paying special attention to the children experiencing the PE lesson rather than the teacher delivering it: 'Watch, watch, watch and we will maybe go three weeks of you watching and slowly but surely, I want you within that three weeks to build a relationship with the students by just tapping into certain little things'. Gareth's rationale for focusing on the children is two-fold: 
one, it helps NQTs to develop a relationship with the children; and, two, it allows NQTs to develop a sense of the needs and capabilities of the children within a PE lesson. Here, Gareth expands thus:

when you get your students [pre-service teachers] to come in, you have to say to them this is the clientele [children] you've got in front of you because you've come in but you don't know the children. How can you come in and perform if you don't know the children? A new teacher, qualified, how can you come in and say you are going to do this and you're going to do that when you don't know the capabilities and the understanding?

This outlook supports the findings of Maher et al. (2019) who identified the use of lesson observations as part of a wider suite of situated learning experiences (Lave and Wenger, 1991) for getting a better sense of the needs and capabilities of pupils in special schools. It is worth noting, as Maher et al. (2019) did, that understanding the needs and capabilities of pupils, especially those with SEND, can be more challenging to establish given that learning needs and specific impairments can be diverse and change over time. Therefore, those who facilitate the professional learning of teachers need to be commitment to 'continued' professional development to ensure that teacher knowledge and skills are current and appropriately situated. This, according to Armour (2006), is essential for pupils' continued learning.

\section{PE-specific CPD should be tailored to the needs of staff and pupils in schools}

Considering the reported inadequacies of ITE and CPD opportunities for upskilling special school PE teachers for their role, all participants, regardless of whether or not they were initially trained to deliver PE, talked about the importance of gaining PE-specific professional development opportunities. Jessica, for instance, explained: 'It's like anything else, you need the correct way of doing it [teaching PE]. At the end of the day, I'm not a PE teacher. We try our best, but if we could have some professional help, then that's even better'. It is noteworthy 
that Jessica emphasises the idea of 'correct' practice in PE, an outlook that perhaps needs to be broadened through CPD. Instead, an appreciation needs to be nurtured through CPD that enables practitioners to become confident and creative, be willing to not get it right all the time, but be able to reflect and then try something different.

When it came to what the CPD opportunities should entail, ideas differed. Adam, for example, focused on multi-skills and skill development:

I think if I was doing one [a CPD course], I'd give kind of the basic skills for teaching. I think multi-skills would be my biggest focus because I think if they're taught well, then the children can develop the skills... if I just had a day, for example, to teach, I'd probably go with how to deliver multi-skills in a PE setting, and how to develop those fine, gross motor skills, balance, co-ordination, all the skills that once unlocked would allow students to access sport in a wider context.

It is perhaps unsurprising to hear this given that Adam is a trained PE teacher, and that skill development and skill-based pedagogies have continued to dominate perceptions about the nature and purpose of PE, something that has been strengthened through the latest National Curriculum in England (DfE, 2014). Indeed, it is widely accepted now that motor abilities such as balance and coordination, which offer the foundations to movement skills such as throwing and hoping, form the basis of the sport-specific skills necessary for sports participation (Lubans et al., 2010). In fact, the significance of this focus perhaps increases given that some children in special school, such as those with autism spectrum conditions (ASC), have demonstrated impaired motor abilities relative to non-disabled peers (Dewey et al., 2007). Therefore, a greater focus on the development of fundamental movement skills may go some way to redressing this 'ability' gap. That said, we would encourage CPD that develops these kind of physical skills in a balanced way, which is also attentive to personal, cognitive and creative skills. 
Whilst Adam focused on the development of movement skills, Sophie wanted CPD opportunities that were impairment or 'need' specific:

I [have] no idea about pupils with autism, and how you make PE effective and relevant to them. If people who were really trained in autism, it would be great if they could ... do you know what I mean, just have people in every kind of area, because it's so different, what we do ... possibly might not be relevant to them.

Sophie continued:

Yeah, for autistic ... but to have it not just like PE for special needs, because the range is massive... we have deaf-blind pupils who are also in wheelchairs, and how you get them to access things as much as you can, and I think we do quite a good job here, but I'm sure there are things that we haven't accessed or we don't know about.

Of particular interest here is Sophie's recognition of the diversity and complexity of pupil needs that are present in some special schools. Sophie clearly articulates the need for more insight about different kinds of impairments. Whilst Sophie's concerns may seem rooted in deficit ideologies of SEND (Oliver, 2013), in that she wants to learn more about specific impairments of pupils, we would suggest this response demonstrates a recognition that she needs to better understand the mechanism of impairment in order to support the particular pupils she works with. The challenge for CPD is to sensitively balance how knowledge of impairment is conveyed in a manner that does not reduce understandings of pupils to mere deficit ideologies. The coupling of impairment with PE CPD needs to be thought-out in a manner that promotes a rounded understanding of the whole child. Here we concur with Armour and Yelling's (2004) call for CPD that moves beyond a diet of subject knowledge and skills and instead invites practitioners to immerse themselves in the "personal, moral and political dimensions of teaching as a professional activity' (p. 98). While none of the participants explicitly mentioned 
the need for their professional learning to be situated, they all talked about the activities that were appropriate to the contexts they work and needs of the children they teach.

\section{Concluding remarks}

This article used situated learning theory and wider processes of professional learning to explore the ITE and CPD experiences of special school PE teachers because, hitherto, this area of research has been largely neglected. It was found that all the teachers in the study, regardless of their professional socialisation, argued that there was a lack of focus on SEND and inclusion and, for some, PE, during their ITE. Therefore, we would like to renew calls for issues relating to SEND and inclusion to become a more prominent feature of ITE programmes in all countries as part of the process for developing a good practitioner, rather than seeing these areas of work as tokenistic add-ons. What this training should entail is up for discussion, and therefore needs to be a continued focus of future research. From what we have learned, a generic focus where the principles of inclusion are mapped out may offer a useful foundation but this then needs to be situated within special school PE; that is, applied to different activities in a variety of spaces and environments given that learning is contextual, situational and can change over time and across space.

For some of the teachers, a special school-based placement, as a situated learning experience during ITE, was one potential avenue for better preparing them for their role as inclusive educators. Whilst there is a growing body of research that casts light on the potentials of such situated learning experiences during ITE, much more research is required that endeavours to explore the support mechanisms and specific learning experiences that pre-service (special school) PE teachers should be exposed to as part of their professional socialisation. This is 
especially important if used within the cultural contexts of different countries. Similarly, it is crucial that our research profession explore the long-term influence of special school-based placements on the attitudes, knowledge, skills and confidence of special school PE teachers given that some or even much of this can be washed out during occupational socialisation (Zeichner and Tabachnick, 1981).

According to the special school PE teachers in this study, there were very few opportunities for PE-specific inclusion training as part of their professional development. This is especially problematic given that some of the participants were not qualified teachers of PE. In many instances, they were expected to 'do what they could' and to 'try their best'. Inevitably, this restricted the extent to which teachers felt they could plan and deliver appropriately challenging and meaningful activities in PE. There were, however, opportunities for more informal professional development through conversations within and across special schools. These conversations, though, were often ad-hoc and opportunistic. There is, therefore, a definite need to re-consider how a range of CPD opportunities, formal and informal, teacher- and school leadership-driven, can support teachers in special schools to develop and grow as part of a broader community of practice. Our research community certainly has a part of play in this respect. However, there is ongoing debate about what this CPD should entail. For the special school PE teachers in our study, it was essential that professional development needed to be bespoke and tailored given the diversity of pupil needs and capabilities within and across special schools. In many ways, this kind of CPD training would attend to the immediate needs of practitioners in relation to the young people they are supporting. We recognise this is an important ingredient to effective CPD, responding to teachers' needs and interests (Parker \& Patton, 2017). Like Armour and Yelling (2004) we would also point to the need for CPD to be a more sustained and holistic endeavour that can move beyond this immediacy and also attend 
to the wider social, political and professional challenges, opportunities and responsibilities of working in schools. Here, future research is required that explores what CPD works best, for whom, in which contexts and situations and how this can be developed to enrich a rounded approach to the career-long professional activity of practitioners. Hitherto, we argue, CPD generally and inclusion specifically have been based on a 'one size fits all model', an approach which does not seem particularly useful to many PE teachers, especially those working in special schools.

Through this research, we hope that we will inspire more academics to focus on special schools as valuable educational contexts for learning about issues relating to SEND, inclusion and inclusive pedagogies.

\section{References}

Australian Institute for Teaching and School Leadership (AITSL) (2010) Australian professional standards for teachers. Retrieved from https://www.aitsl.edu.au/docs/default$\underline{\text { source/teach-documents/australian-professional-standards-for-teachers.pdf }}$

Armour, K. (2006) Physical education teachers as career-long learners. Physical Education and Sport Pedagogy 11(3), 203-207.

Armour, K. \& Yelling, M. (2004). Continuing professional development for experienced Physical Education teachers: Towards effective provision. Sport, Education and Society, 9 (1), 95-114. 
Arthur-Kelly, M., Sutherland, D., Lyons, G., Macfarlane, S., \& Foreman, P. (2013). Reflections on enhancing pre-service teacher education programmes to support inclusion: perspectives from New Zealand and Australia. European Journal of Special Needs Education 28 (2), 217233.

Avalos, B. (2011). Teacher professional development in Teaching and Teacher Education over ten years. Teaching and Teacher Education 27 (1), 10-20.

Backman, E., \& Larsson, H. (2016). What should a physical education teacher know? An analysis of learning outcomes for future physical education teachers in Sweden. Physical Education and Sport Pedagogy, 21 (2), 185-200.

British Educational Research Association (BERA) Ethical guidelines for education research (2nd ed). London: BERA.

Braun, V., \& Clarke V. (2013) Successful qualitative research: a practical guide for beginners. London: Sage.

Braun, V., Clarke, V., Hayfield, N., \& Terry, G. (2018). “Thematic analysis” In P. Liamputtong (Ed.), Handbook of research methods in health social sciences (pp.1-18). Singapore: Singer. 
Bruner, J. (2006) In search of pedagogy. London: Routledge.

Capel, S., Hayes, S., and Katene, W. (2011) The interaction of factors which influence secondary student physical education teachers' knowledge and development as teachers. European Physical Education Review, 17 (2), 183-201.

Chambers, F. (2015). Mentoring in physical education and sports coaching, London: Routledge.

Coates, J. (2012). Teaching inclusively: Are secondary physical education teachers sufficiently prepared to teach in inclusive environments? Physical Education and Sport Pedagogy, 17 (4), 349-365.

Commonwealth of Australia (2006) Disability standards for education 2005 plus guidance notes. Retrieved from https://docs.education.gov.au/system/files/doc/other/disability_standards_for_education_200 5_plus_guidance notes.pdf 
Dart, G. (2006). 'My eyes went wide open' - an evaluation of the special needs education awareness course at Molepolole College of Education, Botswana. British Journal of Special Education, 33 (3), 130-138.

Dely, L. Elliot, D., \& Campbell, T. (2015) 'Really on the ball': exploring the implications of teachers' PE-CPD experience. Sport, Education and Society, 20(3), 381-397.

Department for Education (DfE) (2018). Special educational needs: an analysis and summary of data sources. London: DfE.

Department for Education (DfE) (2014). The national curriculum in England: Key stages 3 and 4 framework document. London: DfE.

Department for Education (DfE) (2011). The teachers' standards. London: DfE.

Department for Education/Department of Health (DfE/DoH) (2015). Special educational needs and disability code of practice: 0 to 25 years. London: DfE/DoH.

Department of Education and Science (DES) (1978). Special educational needs: report of the committee of enquiry into the education of handicapped children and young people. DES: London. 
Dewey, D., Cantell, M., \& Crawford, S. (2007). Motor and gestural performance in children with autism spectrum disorders, developmental coordination disorder, and/or attention deficit hyperactivity disorder. Journal of the International Neuropsychological Society, 13, 246-256.

Ellins, J., \& Porter, J. (2005). Departmental differences in attitudes to special educational needs in the secondary school. British Journal of Special Education 32 (4), 188-195.

Fitzgerald, H. (2005). 'Still feeling like a spare piece of luggage'? Embodied experiences of (dis)ability in physical education and school sport, Physical Education and Sport Pedagogy $10(1), 41-59$.

Florian, L., \& Linklater, H. (2010). Preparing teachers for inclusive education: using inclusive pedagogy to enhance teaching and learning for all. Cambridge Journal of Education 40 (4), 369-386.

Golder, G., Jones, N., \& Eaton-Quinn, E. (2009). Strengthening the special educational needs element of initial teacher training and education. British Journal of Special Education 36 (4), 183-190.

Haegele J., Hodge, S., Barbosa Gutierres Filho, P., \& Goncalves de Rezende, A. (2018). Brazilian physical education teachers' attitudes toward inclusion before and after 
participation in a professional development workshop. European Physical Education Review $24(1), 21-28$.

Haycock, D., \& Smith, A. (2011). 'Still 'more of the same for the more-able?' including young disabled people and pupils with special educational needs in extra-curricular physical education. Sport, Education and Society, 16 (4): 507-526.

Hegarty, S. (2007). "Special education and its contribution to the broader discourse of education” In L. Florian (Ed.), The Sage handbook of special education (pp. 528-536). London: Sage.

Korthagen, F. (2010) Situated learning theory and the pedagogy of teacher education: Towards an integrative view of teacher behavior and teacher learning. Teaching and Teacher Education, 26, 98-106.

Lave, J. \& Wenger, E. (1991). Situated learning: legitimate peripheral participation. New York: Cambridge University Press.

Lubans, D., Morgan, P., Cliff, D., Barnett, L., \& Okely, D. (2010). Fundamental movement skills in children and adolescents. Sports Medicine, 40 (12), 1019-1035. 
Maher, A. (2018). "Disable them all": SENCO and LSA conceptualisations of inclusion in physical education. Sport, Education and Society, 23 (2), 149-161.

Maher, A., Morley, D., Fimusanmi, J., \& Ogilvie, P. (2019) University student experiences of a special school physical education placement. European Physical Education Review, (25) 2, 474-490.

Mawhinney, L. (2010). Let's lunch and learn: professional knowledge sharing in teachers' lounges and other congregational spaces. Teaching and Teacher Education 26 (4), 972-978.

Ministry of Social Development (2016). New Zealand disability strategy 2016-2026.

Retrieved from https://www.odi.govt.nz/assets/New-Zealand-Disability-Strategy-files/pdf-nzdisability-strategy-2016.pdf

Office for Standards in Education (Ofsted) (2018). About us. Retrieved from https://www.gov.uk/government/organisations/ofsted/about

O’Leary, N., Longmore, C., \& Medcalf, R. (2014). The influence of occupational socialisation upon a teacher's interpretation and delivery of teaching games for understanding to pupils experiencing social and emotional behavioural difficulties. Support for Learning 29(1), 57-75. 
Oliver, M. (2013). The social model of disability: thirty years on. Disability and Society, 28 (7), 1024-1026.

Parker, M., \& Patton, K. (2017). What research tells us about effective continuing professional development for physical education teachers. In C. Ennis (Ed.), Routledge handbook of physical education pedagogies (pp. 447-460). Routledge: London.

Richards, K., \& Wilson, W. (2019). Recruitment and initial socialization into adapted physical education teacher education. European Physical Education Review. E-pub ahead of print. Retrieved from: https://doi.org/10.1177/1356336X18825278

Ruscitti, R., Thomas, S., \& Bentley, D. (2017). The experiences of students without disabilities in inclusive physical education classrooms: a review of literature. Asia-Pacific Journal of Health, Sport and Physical Education, 8 (3), 245-257.

Sport England (2001). Disability survey 2000: survey of young people with a disability and sport. London: Sport England.

United Nations Educational, Scientific and Cultural Organisation (UNESCO) (2017). Education and disability, factsheet no. 40, February 2017. Retrieved from http://uis.unesco.org/sites/default/files/documents/fs40-education-and-disability-2017-en.pdf 
World Health Organization (WHO) (2016). Disability and health, factsheet, November 2016. Retrieved from http://www.who.int/mediacentre/factsheets/fs352/en/

Vickerman, P. \& Coates, J. (2009). Trainee and recently qualified physical education teachers' perspectives on including children with special educational needs. Physical Education and Sport Pedagogy 14 (2), 137-153.

Vickerman, P. \& Maher, A. (2018). Teaching physical education to children with special educational needs and disabilities (2nd Ed.). London: Routledge.

Warnock, M. (2010). Special educational needs: a new look. In L. Terzi (Ed.), Special educational needs: a new look (pp. 11-45). London: Continuum.

Wedell, K. (2005) Dilemmas in the quest for inclusion. British Journal of Special Education $32(1), 5-11$.

Zeichner, K., \& Tabachnick, B. (1981). Are the Effects of University Teacher Education "Washed Out" by School Experience? Journal of Teacher Education 32(3), 7-11. 